DOI: $10.5216 /$ racs.v4.59231

\title{
Reflexões sobre uma prática pedagógica construída e vivida no contexto da formação de professor intercultural
}

Harawana Karajá ${ }^{1}$

\section{RESUMO}

Quando eu comecei a pesquisa de estágio pedagógico do curso de Educação Intercultural de Formação Superior Indígena da UFG, tive muitas dificuldades. Após dois anos, peguei muita experiência com os anciãos e as anciãs da comunidade da aldeia. Aprendi através da minha pesquisa e também com os anciãos e as anciãs, assim, aprendi conhecimentos do Iny, autodenominação do povo Karajá. Articulei todos os conhecimentos que eu trouxe para minha mente. Espero contribuir com a valorização dos nossos conhecimentos. Recordei e aprendi muito conhecimento do conjunto Iny, denominado, por nós, Karajá de bdedỹỹnana. Minha experiência, no estágio, é da busca de conhecimento. O estágio realizou-se na aldeia Btoiry, na Ilha do Bananal, Tocantins.

PALAVRAS-CHAVE: Estágio. Conhecimento. Karajá. Valorização.

\section{Rybèna relekre timybo tyyrtina bdèdỹỹnana rèlèmyhỹremy ta timybo rỹiramy, tyyrtidu butu bdèèryna rbi rièrymyhỹre bdèdỹ̃̃nana}

\section{RYBÈNA YJA}

Rèòrarunyreu wapesquisa estágio pedagógico-ò watyyrinaki aõmaki Educação Intercultural de Formação Superior Indígena UFG-ki, sõèmy isiramy tai rahare. Irbi inatxi wyra rèwydi tahè sõèmy bdè nadieryde, ixỹ-my iny iumy mahãdu rỹira rbi. Wapesquisa brò rbi, tasỹ kiarbire iny iumy mahãdu rbi, myỹ hèka iny bdèdỹỹnana reeryre. Butumy reeryre warayky-ò rèbutunyre. Tahè idi ãriraòmy ãrarekre ratyhydỹỹkremy iny bdèdỹỹnana rỹira. Itxi wanohõti rèamy tahè ixby nadieryde iny bdèdỹỹnana, kiamy tahè iny rièrymyhỹrènyre Karajá bdèdỹỹnanamy. Waèrysyna kiamyre estagio-ki iny bdèdỹỹnana raerykremy. Kiaki hèka estagio relere Btõiry hãwa-ki, Bananal-my raninimyhỹreki Tocantin-ki.

RYBÈ WÈRYNA: Estágio. Bdèkèryna. Iny. Tyhydkỹna.

\footnotetext{
${ }^{1}$ Licenciado em Educação Intercultural pelo Núcleo Takinahakỹ de Formação Superior Indígena (NTFSI) da Universidade Federal de Goiás (UFG). Professor da Educação Básica, na aldeia de Btoiry, na Ilha do Bananal/TO. Pesquisador do PIBID/CAPES. Aldeia Btoiry, TO, Brasil. E-mail: harawana2014@ gmail.com.
} 


\title{
Reflections on Pedagogical Practice Developed and Experienced in the Context of Intercultural Teacher's Training
}

\begin{abstract}
When I started my internship research at the UFG Indigenous Higher Intercultural Education course, I had many difficulties. After two years, I gained a lot of experience with the elders of the village community. I learned through my research and also from the elders, so I learned knowledge of Iny, self-denomination of the Karajá people. I articulated all the knowledge I brought to my mind. I hope to contribute to the enhancement of our knowledge. I remembered and learned a lot about the Iny ensemble, which we called Karajá of bdedỹỹnana. My experience at the internship is in the pursuit of knowledge. The internship took place in the village Btoiry, in Bananal Island, Tocantins.
\end{abstract}

KEYwORDS: Stage. Knowledge. Karajá. Appreciation.

\section{Introdução}

As crianças Iny estão retomando os conhecimentos ancestrais por meio das pesquisas com os anciãos e as anciãs. As crianças estão aprendendo muitas coisas, como por exemplo, a confeccionar uma peça de artesanato. Com isso, nossos saberes tradicionais estão sendo atualizados. A escola está contribuindo com esse processo. Por isso, é muito importante a escola ter projetos para atender a necessidade da comunidade. Ter um bom projeto de alfabetização que se contextualize na realidade da criança, e fundamentado no conhecimento do mundo onde a criança vive. A alfabetização precisa de um projeto que considere o mundo no qual as crianças vivem como elas são ensinadas e como elas adquirem os conhecimentos ligados ao patrimônio cultural, como por exemplo: as danças, músicas, jogos, manifestações culturais, os nomes dos animais, das aves, dos peixes, dos artesanatos, buscando fortalecer os conhecimentos nossos.

Antigamente, os conhecimentos do povo Iny eram só na oralidade, mas recentemente estamos registrando esses conhecimentos. Essas ideias, fui adquirindo durante meu período de estágio do Curso de Educação Intercultural da Universidade Federal de Goiás. Assim, apresentarei, a seguir, minhas experiências com as etapas do estágio.

\section{Minha experiência pedagógica no Estágio I}

No meu primeiro estágio, comecei com muitas dificuldades, não sabia fazer plano de aula, pesquisar, organizar a pesquisa para ser trabalhada com meus alunos em um plano de 
aula. Ainda tinha o plano de estudo, uma exigência da minha orientadora, a professora Maria do Socorro Pimentel da Silva. Cada estagiário precisa ter um plano de estudo, que é composto de leitura de textos de orientação, o cronograma de pesquisa, organização da pesquisa e plano de aula. Meu primeiro tema contextual foi 'Wiu bdedyynana' (música tradicional). Busquei, durante uma semana, conhecimentos da anciã daqui da nossa aldeia. Com ela levantei muitos conhecimentos. Aqui na minha aldeia tem muitos conhecimentos. Então, por que me interessei sobre música? Porque hoje em dia estamos esquecendo nossa tradição, nosso costume, pintura corporal, dança, cantos etc. Por isso, é importante para comunidade registrar, documentar, deixar escrito alguns rituais. Hoje em dia, muitos jovens não sabem dançar, cantar, praticar rituais, por isso, temos que retomar as músicas que estão desaparecendo, então, neste estágio, fizemos algumas reflexões importantes, e juntei todo meu aprendizado e registrei no meu projeto de estágio, ou melhor, no meu relatório.

\section{Estágio II: tema contextual "Brincadeira Iny"}

O meu trabalho foi realizado na aldeia Fontoura, por meio da pesquisa com pessoas mais velhas da comunidade. Entrevistei a anciã da aldeia, no dia 24 de agosto de 2016, na quarta-feira, a partir das $9 \mathrm{~h}$ da manhã. A entrevistada se chama Ximalaki Karajá. Fiz as perguntas junto com alunos, para ela, sobre a brincadeira Iny e ela explicou cada pergunta detalhadamente. As meninas brincavam separadas, brincavam de melancia, e os meninos brincavam de onça. Foi importante para os alunos aprenderem as brincadeiras Iny, e se conscientizarem sobre a importância de documentar nossas brincadeiras, pois cada ano que passa estão morrendo os anciãos e anciãs, da aldeia, levando com eles e elas essa sabedoria, por isso é importante documentar para garantir vitalidade da cultura, entre gerações. É importante brincar também. A brincadeira traz muita alegria e equilíbrio para as pessoas. Deixam as pessoas mais felizes.

Quando dei a primeira aula para os alunos, eles tiveram muitas dificuldades. Depois os alunos aprenderam o que é tema contextual. Os alunos aprenderam muito, trocamos nossos conhecimentos entre a gente. Eu e meus alunos vamos ensinar nossa comunidade a retomar nossas brincadeiras Iny. Esse é meu raciocínio, vamos conscientizar nossas crianças e fortalecer nossa cultura. Nas ideias dos alunos, temos que fazer reunião com a comunidade. Eles querem saber a opinião da comunidade. É bom respeitar a ideia de cada aluno. 


\section{Estágio III: tema contextual "Ritxoo"}

No Estágio III, escolhi o tema contextual "RITXOO”. No dia 18 de março de 2017, na parte da manhã, num sábado, fiz entrevista com a anciã da aldeia Fontoura, sobre a situação da ritxoo, porque hoje em dia nós estamos perdendo o conhecimento sobre ritxoo (boneca de cerâmica) que não está sendo feita em Fontoura, corremos o risco de perder esse saber. Minha comunidade era reconhecida por ter grandes ceramistas. Por isso, quis pesquisar sobre essa realidade e conhecer mais das histórias das ritxoo. Nesse estágio, meus objetivos foram: (1) Valorizar a ritxoo; (2) Debater com os alunos/as sobre a situação da ritxoo, porque as ceramistas da aldeia estão morrendo, por isso que estou fazendo esse trabalho com esse conhecimento; (3) Mostrar para as meninas como essa arte é feita. Esta é uma atividade feminina. Daí a importância de promover uma articulação das crianças com as ceramistas, ou seja, as que ainda têm esse saber. Minha meta também era problematizar o impacto da cultura do branco sobre a nossa. Muitas vezes, vejo que minha cultura está penando, por isso evoco minha comunidade para pensar sobre ritxoo. Esta arte também contribui com nossa situação financeira. Assim, fazer essa arte é fazer nosso conhecimento e também garantir renda para o sustento das famílias.

Para contextualizar o tema, apresentei, em slides, diferentes tipos de ritxoo. Expliquei verbalmente cada detalhe das ritxoo. Quem fez essa explicação foi uma ceramista idosa. Ela dialogou com os alunos. Os alunos pesquisaram também e apresentaram em sala de aulas seus estudos. Nosso objetivo é buscar melhoria da cultura indígena. Essa é nossa ideia do povo Iny, aliás, de todos nós professores indígenas. As bonecas de cerâmica nós construímos para vender, para as crianças brincarem. As alunas aprenderam muito rápido os conhecimentos. Fizeram aulas práticas de cerâmicas, como mostram as imagens a seguir.

Fotos 1 e 2 - As meninas Iny aprendendo a fazer as bonecas ritxoo.

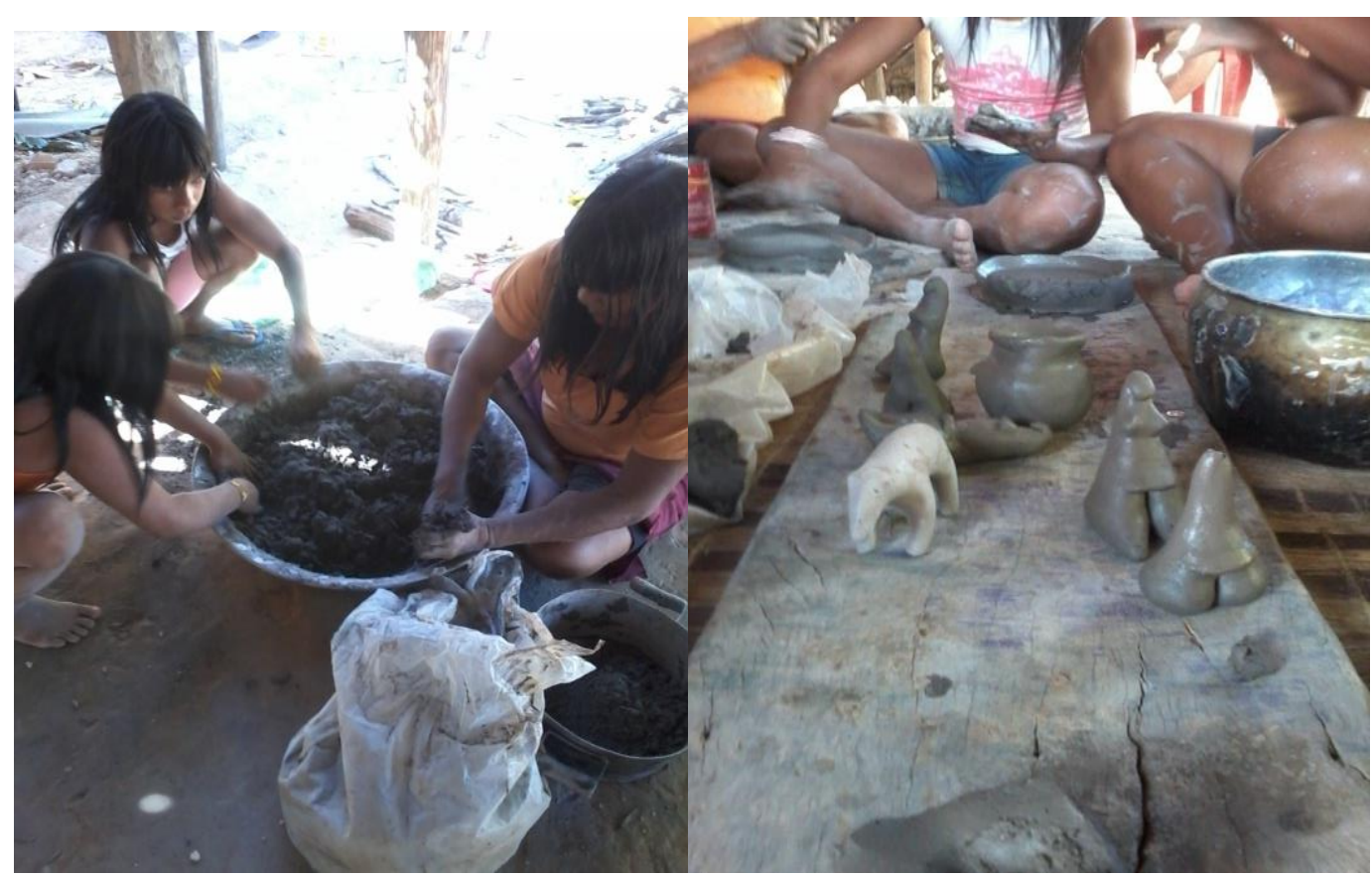

Fonte: Harawana Karajá, 2017. 
Foto 3 - Bonecas ritxoo.

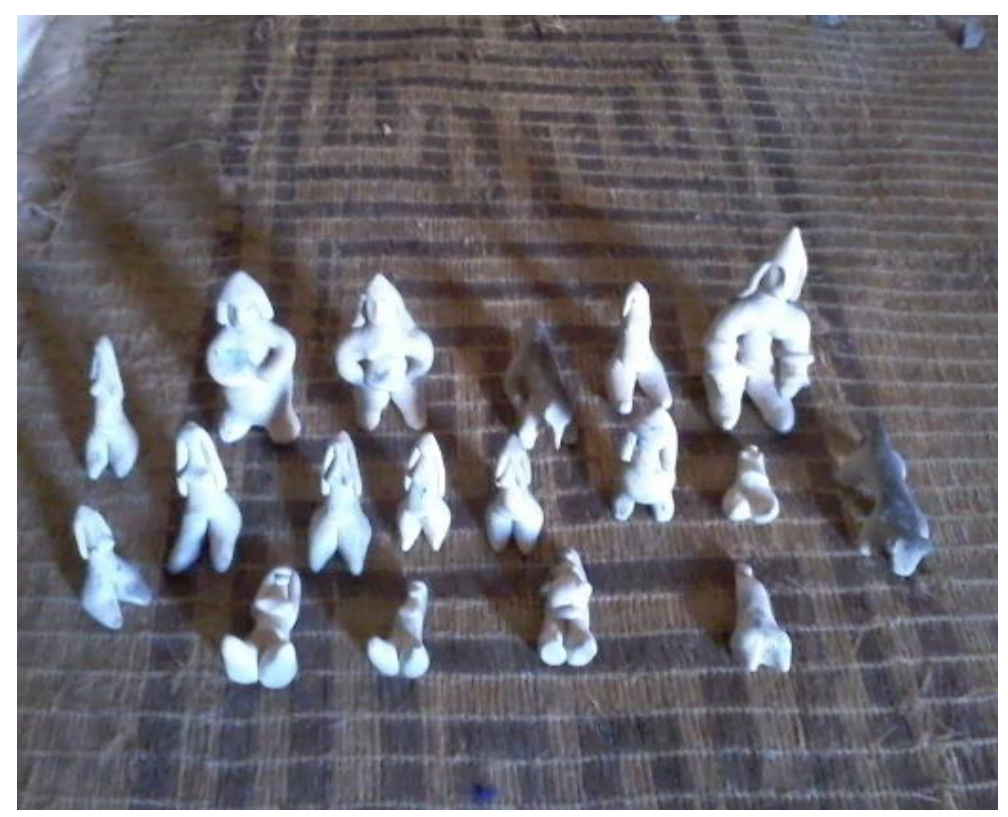

Fonte: Harawana Karajá, 2017.

Os meninos fizeram os relatórios das aulas, pois eles não fazem ritxoo, que é uma atividade feminina, de acordo com as regras de meu povo. As meninas participaram das aulas práticas coordenadas pela anciã. As alunas gostaram muito e acharam a ideia nova e querem avançar muito nesse conhecimento. A concepção delas é conhecer mais dos materiais da produção das ritxoo, mas também de mais conhecimentos sobre: pintura corporal, artesanato, remédio tradicional etc. Até eu, como professor, elas me deram reflexões novas. Elas aprenderam muito através das aulas práticas. Então, este foi o trabalho que realizei nessa etapa de estágio.

\section{Estágio IV: tema contextual "Lixo na Aldeia"}

No dia 03 de setembro de 2017, domingo de manhã, às 9h, pesquisei com uma agente de saúde sobre o lixo da nossa aldeia, a pergunta foi assim: o lixo está sujando nossa aldeia, como é que faz para minimizar um pouco desse lixo? Será que tem algum conselho para a comunidade, sobre lixo que tem dentro da aldeia? Como tratar este lixo? Meu desejo com essas perguntas era conseguir organizar um material para discutir sobre o lixo. Conscientizar meus alunos, a escola e a comunidade sobre os perigos do lixo, as doenças que eles podem causar. A ideia era também, que, uma vez por semana, um agente de saúde fizesse uma palestra na comunidade sobre a questão da coleta de lixo, assim a criança vai entender sobre lixo. É muito importante entender, porque, às vezes, alguém na comunidade não entende, 
porque agente de saúde não trabalha sobre a questão do lixo, por isso que escolhi esse tema. É importante que os alunos aprendam na escola e ensinem na sua família como cuidar do lixo. Para atingir meus objetivos, problematizei a questão mostrando para meus alunos que o lixo traz muitas coisas ruins para todos da comunidade e para a saúde indígena. Quando a gente faz feira na cidade, trazemos a compra para a aldeia numa sacola de plástico e quando a gente chega em casa deixa a sacola no chão e elas vão se espalhando na aldeia, e vai acumulando sujeira. Com isso, as crianças pegam diversas doenças através do lixo. Este tema foi muito importante. As crianças analisaram essa questão do lixo. Deixou suas reflexões escritas. Escreveu e desenhou sobre os cuidados que se deve ter com o lixo.

Minha metodologia, nessa aula, foi para a escola e para a comunidade. Os alunos fizeram cartazes e ensinaram em casa sobre o lixo. Eles fizeram cartazes com desenhos da aldeia com o lixo e depois sem o lixo. Tratar o lixo é muito importante. Não jogar lixo no rio Araguaia também.

Os alunos e alunas fizeram trabalho em grupo sobre o lixo e as doenças que causam para os seres humanos e para o meio ambiente.

Fotos 4 e 5 - Trabalho em grupos sobre o lixo e as doenças.

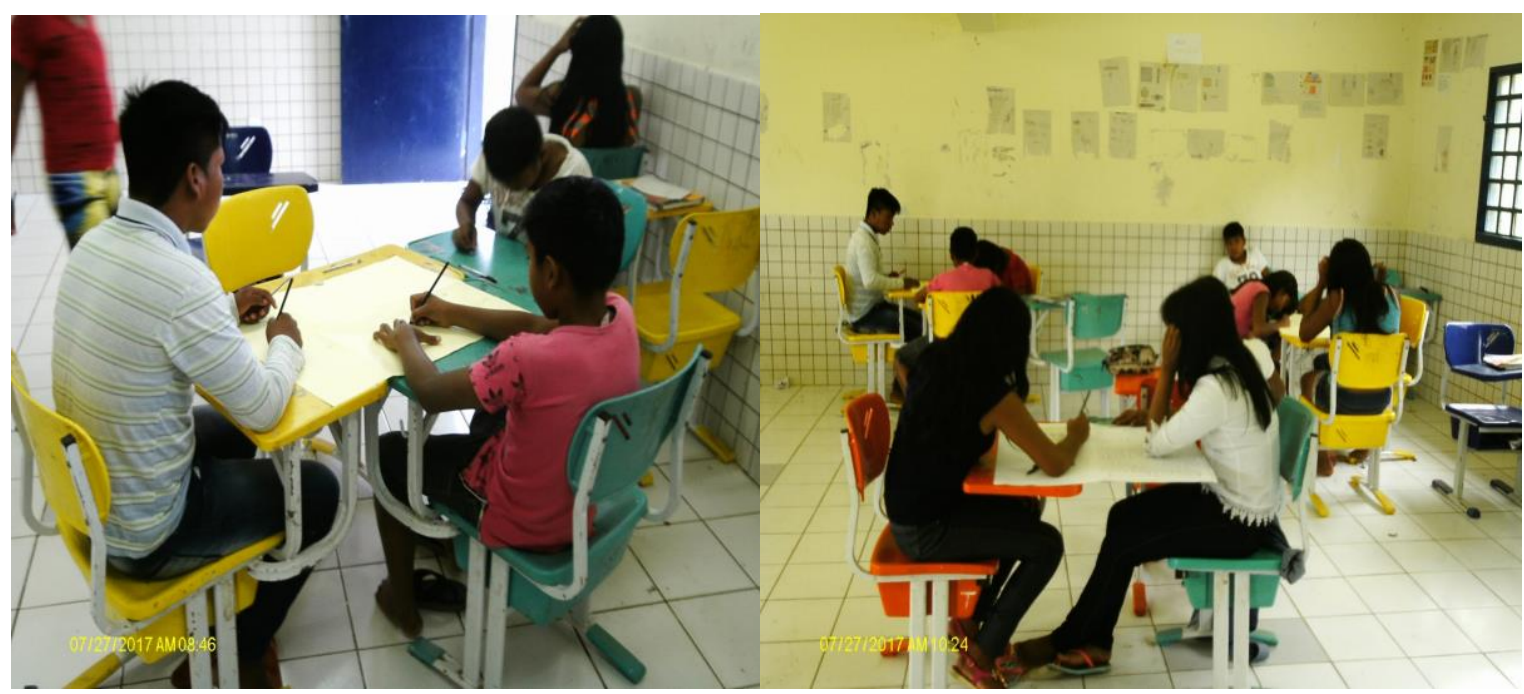

Fonte: Harawana Karajá, 2017. 
Foto 6 - Trabalho em grupo sobre o lixo e as doenças.

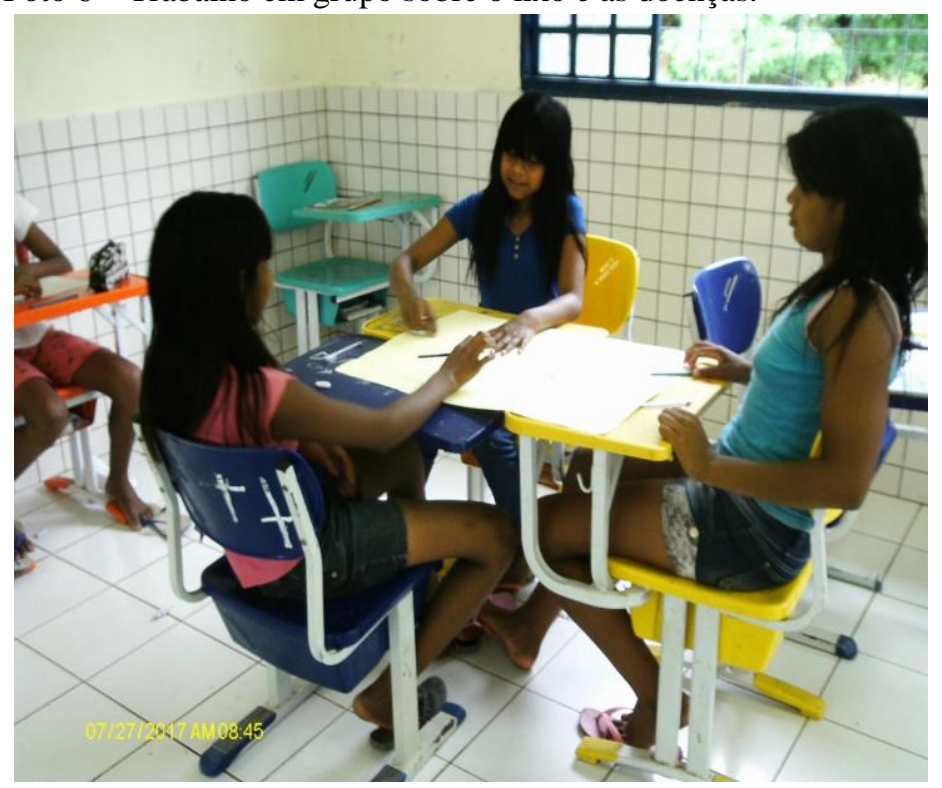

Fonte: Harawana Karajá, 2017.

Todos/as estão contextualizando sobre o lixo na aldeia. Agora estão preocupados com o lixo, por isso, tem estudante escrevendo o que está errado na aldeia. Estão discutindo pela primeira vez que a agente de saúde não se preocupa com nossa comunidade. Ela não informa nossa comunidade sobre os perigos do lixo, como cuidar do lixo de modo certo. É muito importante dar conselho, para nossa comunidade, na área de saúde, que trabalhe bem cuidadosamente porque tem muitas crianças aqui. Depois que os trabalhos ficaram prontos, foram apresentados, e aconteceram muitos debates. A ideia é de os estudantes aprenderem sobre o lixo e ensinar a sua família. Isso é importante para a saúde da nossa comunidade. Penso assim como professor.

Foto 7 - Apresentação dos trabalhos.

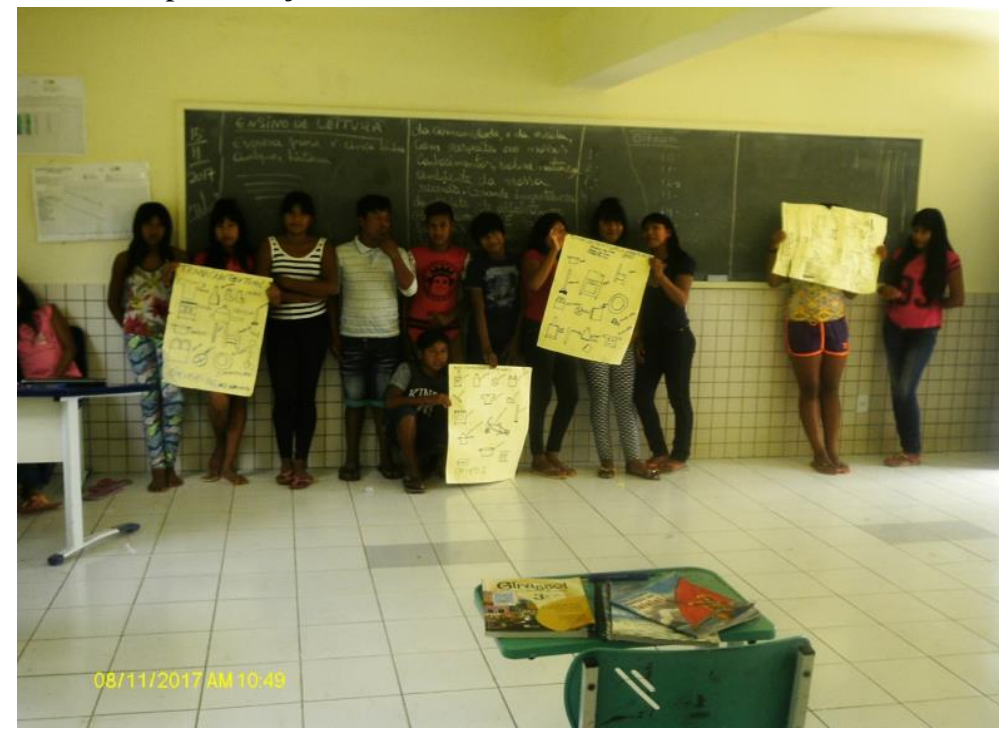

Fonte: Harawana Karajá, 2017.

R. Articul.const.saber, 2019, v.4: e59231 
Foram cinco dias de aulas. Então, os alunos debateram, discutiram, relataram, fizeram uma palavra, com cartolina, contra lixo da aldeia, porque eles querem a aldeia sempre limpa. Minhas aulas foram de manifestação contra o lixo. O objetivo maior é cuidar bem de nossa comunidade. Evitar que as pessoas fiquem doentes por causa do lixo. As pessoas não sabem, por isso é muito bom quando a escola toma decisão de cuidar de sua comunidade, de suas crianças. Isso é importante para mim.

\section{Estagio V: tema contextual "wyhy waxihate" (Arco e flecha)}

Pesquisar e buscar conhecimentos dos anciãos, sobre arco e flecha, porque hoje em dia nossas crianças não sabem mexer com arco e flecha e também não sabem como é que se faz esse instrumento, nem qual madeira serve para fazer arco. Então, essa questão é muito importante para a nossa comunidade e nossas crianças. A minha concepção é de fortalecer nossa identidade. Hoje em dia criança não tem brinquedo de arco e flecha, por isso que pesquisei em relação à flecha. Meu desejo é abrir um espaço de conversa, ou seja, que os pais ensinem seus filhos esse conhecimento. Quando estamos aprendendo algum saber importante, sempre recebemos conselhos, escutamos histórias, somos educados. Então, não é só aprender fazer a flecha, mas muito mais que isso. Se o menino aprender fazer flecha e mostrar para sua família como aprendeu, aí a família dele fica orgulhosa de seu filho e isso é muito bom.

Trocar conhecimento é muito importante, ou seja, temos que aprender os conhecimentos das ciências não indígenas, mas também os nossos, ambos são importantes, mais uma coisa é certa, sou Karajá com meus conhecimentos, os outros conhecimentos vem do campo das demandas interculturais, da necessidade de convivência com os não índios. Na minha reflexão, posso afirmar que as crianças são mais felizes estudando assim: articulando conhecimentos. Mostro, nas minhas aulas, o que significa deixar nossa cultura enfraquecer. Toda essa problematização é muito importante. O tema contextual, como bem afirma Pimentel da Silva (2017) possibilita a retomada de saberes milenares, fortalecer nossa cultura, mas também ajuda mostrar que os saberes dos indígenas e dos não indígenas podem conviver juntos. É importante trabalhar o conhecimento de modo articulado, considerando a base de construir conhecimento na coletividade. 
Fiz aulas práticas, teóricas, e de muita oralidade, e com isso aprendi parte de construção de artesanato. Fiz aula prática, objetiva, e de incentivo etc. Essa é minha reflexão e ação, ou seja, o de entender todas as chaves metodológicas para criar meios de como proteger nosso conhecimento, de proteger a natureza, criando uma escola bem articulada com a comunidade. A escola sozinha, sem a comunidade, vira escola do tori (não indígena).

\section{Reflexões finais}

No meu último estágio, organizei todo conhecimento que adquiri durante essa experiência. Tornei-me um professor pensador, pesquisador, consciente do meu papel na escola e na comunidade. Entrei na Educação Intercultural sem nenhuma experiência de professor, não era professor. Fiz-me professor nesse curso. Assim, primeiramente, quero fazer agradecimentos para Deus grande, nosso pai, segundo vou para minha orientadora, a professora Maria do Socorro Pimentel da Silva, com ela eu aprendi muitas coisas para minha comunidade, e também aprendi através da pesquisa, na minha comunidade, com os sábios e as sábias de minha comunidade. Carrego em mim muitos conhecimentos dos anciãos e das anciãs da aldeia. Registrei os conhecimentos deles para virar livros didáticos e de documentação dos grandes saberes.

Então, esse foi meu trabalho: aprender com as pessoas que entrevistei em nossa aldeia. Isso me deu força para movimentar meus conhecimentos, esticando-os e espalhando aqui dentro da aldeia. É muito importante ampliar esses conhecimentos na aldeia. Através dessa metodologia, a da contextualização e problematização, espalhei conhecimentos, ensinei os jovens e crianças, também, espalhar conhecimento na comunidade. Minha pesquisa e de meus alunos, cada pesquisa de outros professores, está retomando partes da nossa cultura, e palavras estão renascendo novamente. Isso fortalece o povo Iny. Ficam mais inteligentes para aprenderem os conhecimentos dos não indígenas. Deixam os mais velhos felizes.

O estágio me ajudou a buscar conhecimento com os anciãos e com as anciãs. Fiz isso com meus alunos/as e eles e elas estão retomando os conhecimentos dos ancestrais, falando da importância dos conhecimentos do povo Iny. Isso, na minha reflexão, é segurança cultural. Gosto muito de uma fala da minha orientadora, quando ela diz: quando as crianças indígenas estão aprendendo a confeccionar uma peça de artesanato, estão também adquirindo outros conhecimentos sobre sua cultura e os usos da língua materna, ligados a esses fazeres culturais, conferir Pimentel da Silva (2016). 
Sei que todas as coisas começam nas e pelas bases, por isso, há esperança que minha experiência pedagógica possa ajudar as pessoas a pensarem sobre a realidade atual. Esta é minha esperança e contribuição, como professor. Nossos saberes tradicionais estão se atualizando. Isso pode ser uma base importante para criar livros didáticos desde a alfabetização. O material que vem de fora não atende as demandas da alfabetização na língua das crianças. Não considera o mundo no qual as crianças vivem, como elas são ensinadas, e como elas adquirem os conhecimentos ligados ao patrimônio cultural, como, por exemplo: dança, música, jogo, manifestação cultural, os nomes dos animais, das aves, dos peixes, dos artesanatos. Na minha concepção, esse paradigma está abrindo novos caminhos para o povo Iny. Hoje, o conhecimento da oralidade precisa também da escrita. Foi por meio da escrita que aprendi muito do saber oral do meu povo. Estou fortalecido como Iny. Do meu ponto de vista, temos que fazer reunião junto com jovens, vamos conscientizar a cabeça dos jovens, quer dizer, orientar cada detalhe importante e os jovens saber para falar de suas culturas indígenas. Para isso, é preciso ancião ensinar seus jovens, porque cada dia está perdendo a cultura e precisa do ancião para retomar a cultura, nossa força.

\section{Referências}

KARAJÁ, Ximalaki. Conhecimentos Tradicionais Iny. Aldeia Fontoura.

KARAJÁ, Kurahare. Conhecimentos Tradicionais Iny. Aldeia Fontoura.

PIMENTEL DA SILVA, Maria do Socorro. Impactos da educação na vitalidade do patrimônio epistêmico Iny. Goiânia: Kelps, 2015.

Pedagogia da retomada: descolonização do saber. Articulando e Construindo Saberes. v. 2, n.1, 2017, p. 203-215.

Submetido em 27 de junho de 2019.

Aceito em 29 de julho de 2019.

Publicado em 05 de agosto de 2019. 